\title{
Anterior Dental Cutting in the Laetolil Hominids and the Evolution of the Bicuspid $\mathrm{P}_{3}{ }^{1}$
}

\author{
MILFORD H. WOLPOFF \\ Department of Anthropology, University of Michigan, Ann Arbor, Michigan 48109
}

\author{
KEY WORDS Laetolil - Hominid anterior cutting - Bicuspid \\ $\mathrm{P}_{3}$ evolution
}

\begin{abstract}
The younger Laetolil hominids provide evidence of a unique anterior cutting complex with a chisel-like action occurring between the lingual-distal $\underline{\mathrm{C}}$ face and a transverse ridge on the $\mathrm{P}_{3}$ perpendicular to it, extending between the subequal cusps. An earlier adaptation to more efficient grinding may have resulted in reduced canine projection and the development of the lingual $P_{3}$ cusp, raising the ridge between it and the buccal cusp. This development acted to retain the anterior cutting function by shifting it to the top of the premolar.
\end{abstract}

The Tanzanian site of Laetolil, (Leakey et al., '76), has yielded the earliest large hominid sample known, one million years or more older than the South African australopithecine occurrences. The description of these hominids, (White, '77), mentioned large canine size, canine projection beyond the occlusal plane, a polished wear facet extending across the distal and distal-lingual face of the maxillary canine exposing a sharpened distal edge with thin enamel lingually bordered by exposed dentin in one older specimen, and vertical wear striae on the buccal face of the $\mathrm{P}_{3}$. These form the most primitive $\mathrm{C} / \mathrm{P}_{3}$ complex known for a hominid.

Additional observations suggest a unique age-dependent cutting function for this complex. $\mathbf{P}_{3}$ morphology is known for three specimens: LH 3 (unerupted), LH 4 (dentally oldover 22 years, if age determination criteria applicable to later hominids can be used), and LH 14 (about 18). The teeth are characterized by a dominant buccal cusp, a weaker somewhat lower lingual cusp connected to the buccal cusp by an enamel ridge, mesial and distal ridges extending inferiorly from the apex of the buccal cusp (when unworn), and an elliptical cross section for the crown base (the long axis of the ellipse is approximately transverse, although the buccal side is displaced somewhat mesially). In the oldest specimen, LH 4, the central and distal aspect of the occlusal surface is worn fairly flatly, although the buc- cal cusp and the ridge connecting it to the lingual cusp are higher than the distal surface of the tooth.

However, in the LH $14 \mathrm{P}_{3}$, the transverse ridge connecting the cusps is not rounded from wear. Instead, wear against the opposing $\underline{C}$ and $\mathrm{P}^{3}$ has resulted in transverse flattened facets along the ridge which maintain its sharp edge. An additional wear facet appears on the lingual face of the mesially and inferiorly directed ridge, also extending from the buccal cusp of the $P_{3}$. It is not clear whether this facet also acts to sharpen the mesial ridge.

Comparison of the LH 5 maxilla and the LH 4 mandible shows that the angle of the transverse $P_{3}$ ridge measured to a line drawn through the posterior tooth row matches the angle of the lingual-distal wear facet on the maxillary canine. The direction of the premolar ridge is parallel to the plane defined by the flattened distal $\mathrm{C}$ face. The wear characteristics of the premolars indicate that as the distal-lingual surface of the maxillary canine met the transverse ridge on the lower premolar, a chiseling effect resulted in cutting as these perpendicular surfaces slid across each other. At first, the maxillary canine would be moving primarily mesio-bucally with respect to the premolar. This was when the chiseling/ cutting function took place. As the closing

\footnotetext{
${ }^{1}$ Research supported by a University of Michigan Rackham grant.
} 
motion was completed, the direction of the motion became almost completely inferior, accounting for the vertical striae on the buccal $\mathbf{P}_{3}$ face.

Moreover, differential wear characterizes the teeth involved in this function. Occlusal wear on the $\overline{\mathrm{C}}$ and $\mathrm{P}_{3}$ is much less than on $\mathrm{P}_{4}$. The $\overline{\mathrm{C}}$ and the $\mathrm{P}_{3}$ cusps extended above the occlusal plane as defined by the more posterior teeth. Unlike LH 4, the presence of a distal interproximal facet on the $\mathrm{LH} 14 \overline{\mathrm{C}}$ shows that there was no diastema.

Thus, in the younger Laetolil specimens a chisel-like cutting function was maintained between the distal-lingual surface of the maxillary canine and the transverse ridge connecting the subequal $P_{3}$ cusps. This complex is unknown for any other primate. Moreover, the cutting function was lost in the older Laetolil hominids as occlusal grinding predominated, obliterating the morphology that resulted in cutting. The $P_{3}$ is probably best described as sectorial/bicuspid since it combines bicuspid morphology with an elliptical cross section and a cutting function.

One evolutionary pathway that could have resulted in this morphological complex proceeds along lines suggested by Jolly ('70). If a Miocene hominoid primate with a Proconsul-like dentition came under selection to improve the efficiency of rotary grinding, interlock of the projecting canines would become an obstacle to free transverse movement of the lower jaw. Reduction of canine projection might have resulted in freer transverse motion, but this would also interfere with the cutting function of the distal $\mathrm{C}$ edge against the mesial $\mathrm{P}_{\mathrm{s}}$ edge since the edges could no longer fully meet. The early hominids might have retained the cutting function while improving grinding efficiency by shortening $\mathrm{C}$ height and shifting the position where cutting took place from the mesial-buccal $P_{3}$ face to the top of the $P_{3}$. This allowed the shortened canine to cut (or perhaps more properly chisel) against the $P_{3}$ because the action occurred at the top of the tooth. Moreover, the hypothesis suggests that the bicuspid form of the $P_{3}$ may have appeared earlier in time because the larger lingual cusp raised the position of the (formerly inferiorly directed) transverse ridge, making it nearly horizontal and consequently useful in the chiseling action described above.

However, the appearance of mixed functions for the $P_{3}$ in the Laetolil hominids is indicated by the fact that the ability to cut was lost in older individuals and the tooth was incorporated into the grinding complex. Similarly, in the canines of older individuals, occlusal wear on the tip blunted the tooth to the extent that there was insufficient projection for the distal edge to cut. Later in time, when the cutting function was lost and canine projection was further reduced, the lingual $P_{3}$ cusp became more closely equal to the buccal cusp in size for many specimens.

In sum, the unique mechanism that provides for $\mathrm{C} / \mathrm{P}_{3}$ cutting in the younger Laetolil individuals, and the mixture of cutting and grinding functions for this dental complex, suggests that Laetolil may represent one of the terminal stages in the reduction and functional change of the hominid anterior den tition.

\section{ACKNOWLEDGMENTS}

I thank M. D. Leakey and R. E. F. Leakey of the National Museums of Kenya for permission to study the Laetolil hominid specimens, and Dr. B. A. Ogot, director of The International Louis Leakey Memorial Institute for African Prehistory for the facilities and help provided to me.

\section{LITERATURE CITED}

Leakey, M. D., R. L. Hay, G. H. Curtis, R. E. Drake, M. K. Jakes and T. D. White 1976 Fossil hominids from the Laetolil beds. Nature, 262: 460-466.

Jolly, C. J. 1970 The seed eaters: a new model of hominid differentiation based on a baboon analogy. Man, 5: 5-26.

White, T. D. 1977 New fossil hominids from Laetolil, Tanzania. Am. J. Phys. Anthrop., 46: 197-230. 